
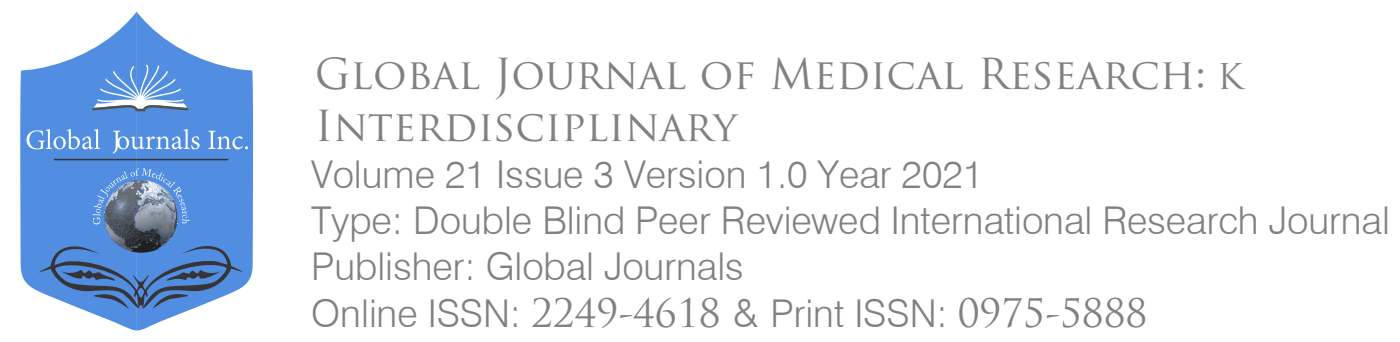

\title{
Prevalence of Anxiety Symptoms in Medical Students in the Inner State of São Paulo, Southeast Brazil
}

By Leonor de Castro Monteiro Loffredo, Rodolpho Telarolli Júnior, Jaquelini Diniz, Gabriel Orlandi de Souza, Gabriela Bombarda Barros, Luiz Carlos Lobato Miani \& Thiago Eduardo Manzi

Universidade Estadual Paulista - UNESP

Abstract- Background: Anxiety is a global health concern among medical students. It is associated with difficulty concentrating, insomnia, and a damaged lifestyle.

Objectives: To describe anxiety symptoms and to assess the prevalence of anxiety in medical students.

Design and Setting: It was conducted a cross-sectional study in a sample of 120 first- to fourthyear medical students in the inner state of São Paulo, Brazil.

Methods: An anxiety symptoms formulary was applied to the medical students. There were estimated the prevalence of anxiety and the prevalence ratios according to the variables age, gender, course year, sleep, physical activity, and use of anti-anxiety medication.

Keywords: mental disorders; anxiety disorders; education, medical, undergraduate; epidemiology; prevalence.

GJMR-K Classification: NLMC Code: WM 165

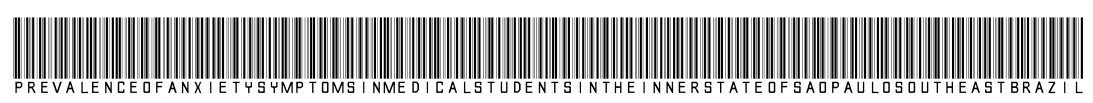

Strictly as per the compliance and regulations of:

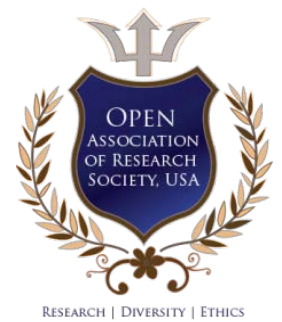

(c) 2021. Leonor de Castro Monteiro Loffredo, Rodolpho Telarolli Júnior, Jaquelini Diniz, Gabriel Orlandi de Souza, Gabriela Bombarda Barros, Luiz Carlos Lobato Miani \& Thiago Eduardo Manzi. This is a research/review paper, distributed under the terms of the Creative Commons Attribution-Noncommercial 3.0 Unported License http://creativecommons.org/licenses/by$\mathrm{nc} / 3.0 /$ ), permitting all non-commercial use, distribution, and reproduction in any medium, provided the original work is properly cited. 


\title{
Prevalence of Anxiety Symptoms in Medical Students in the Inner State of São Paulo, Southeast Brazil
}

\author{
Leonor de Castro Monteiro Loffredo ${ }^{\alpha}$, Rodolpho Telarolli Júnior ${ }^{\circ}$, Jaquelini Diniz ${ }^{p}$, \\ Gabriel Orlandi de Souza ${ }^{\omega}$, Gabriela Bombarda Barros ${ }^{*}$, Luiz Carlos Lobato Miani ${ }^{\S}$ \\ \& Thiago Eduardo Manzi ${ }^{x}$
}

Abstract- Background: Anxiety is a global health concern among medical students. It is associated with difficulty concentrating, insomnia, and a damaged lifestyle.

Objectives: To describe anxiety symptoms and to assess the prevalence of anxiety in medical students.

Design and Setting: It was conducted a cross-sectional study in a sample of 120 first- to fourth-year medical students in the inner state of São Paulo, Brazil.

Methods: An anxiety symptoms formulary was applied to the medical students. There were estimated the prevalence of anxiety and the prevalence ratios according to the variables age, gender, course year, sleep, physical activity, and use of anti-anxiety medication.

Results: The prevalence of mild, moderate and severe anxiety was $31.7 \%, 30.8 \%$ and $7.5 \%$, respectively. There was a significant association of anxiety with age $\left(x^{2}=16.2858\right.$; $p=0.001)$ and gender $\left(x^{2}=11.5165 ; p=0.009\right)$, though it was non-significant for course year, sleep, physical activity, and regular use of anti-anxiety medication ( $p>0.05)$.

Conclusions: Higher rates of anxiety were seen among female and younger students. Better understanding the extent of the problem can help develop and implement interventions in order to control and prevent anxiety among students in medical education institutions.

Keywords (MeSH): mental disorders; anxiety disorders; education, medical, undergraduate; epidemiology; prevalence.

Authors' Keywords: epidemiology. prevalence. anxiety. students, medical. education, medical.

Corresponding Author a: PhD, Associate Professor at Universidade Estadual Paulista - UNESP and Universidade de Araraquara- UNIARA. Araraquara-SP, Brazil.e-mail: Icmloffredo@uol.com.br

Author o: Md, PhD, Associate Professor at Universidade Estadual Paulista - UNESP and doctor in Private Clinic. Araraquara, SP, Brazil.

e-mail: rtjr@terra.com.br

Author p: BsC, Psychologist at Universidade de Araraquara- UNIARA. Araraquara, SP, Brazil.e-mail: jaquelinidiniz8@gmail.com

Author $\omega ¥ \S \chi$ : Medical student at Universidade de AraraquaraUNIARA. Araraquara, SP, Brazil.

\section{InTRODUCTION}

A nxiety is a common state of the body characterized by fear and physical stress, and Iwhen it becomes pathological, anxiety symptoms may affect everyday life. Exposure to traumatic experiences in childhood could explain the origin of anxiety symptoms ${ }^{1}$ and, during life, can be associated with age, gender, cultural background, and economic condition. ${ }^{2}$

Different types of anxiety disorders that can affect daily life to a greater or lesser extent; social anxiety and generalized anxiety have an impact on social life and can make people feel discouraged and anguished. ${ }^{3,4}$

The global prevalence of people suffering from anxiety was $3.6 \%$ in 2015. In the Americas, it was 5.8\%, affecting $9.3 \%$ of the Brazilian population. ${ }^{3}$

A cross-sectional study among 40,348 medical students found a prevalence of $33.8 \%$. It was most prevalent among those from the Middle East and Asia, with no significant association with gender and year of study. ${ }^{5}$

In Brazil, a study with 603 medical students attending medical school (ABC Medical School) found high anxiety scores in $20.1 \%$ and moderate anxiety in $79.9 \%$. Still, there were not reported variations in the prevalence of anxiety symptoms by the medical school year. ${ }^{6}$

A multicenter study of anxiety among Brazilian medical students reported $81.7 \%$ state-anxiety and $85.6 \%$ trait-anxiety, with a significant association with female sex. ${ }^{7}$

Evidence shows that medical students are more likely to have anxiety than the general population, as they go through various transition periods during the course. $^{8}$

Medical students' mental health is a global public health concern, and there is an academic movement calling for medical education institutions to promote medical students' health and well-being by addressing curricular issues and reinforcing their support network. ${ }^{7,9}$ 
Students' academic life routinely involves a high study load and many learning activities and, if their average sleep hours reduces, the anxiety rates increase. They may even reduce their level of physical activity with compromised cardiorespiratory and muscular fitness and behavioral changes.

This study aimed to describe anxiety symptoms and assess the prevalence of anxiety among medical students with respect to the variables: age, gender, course year, sleep, physical activity, and use of antianxiety medication.

\section{Methods}

A cross-sectional study described the anxiety symptoms and assessed the prevalence of anxiety in medical students from a private medical school program in the inner state of São Paulo, Brazil, in 2019.

The study population comprised 677 students enrolled in a private medical education program in August 2019. For a prevalence of anxiety among medical students of $20.1 \%$ as previously reported, ${ }^{6}$ an estimated sample size of 181students was determined with a margin of error to be no more than $\pm 5 \%$ at the 95\% confidence level. The participants were from each one of the 12 learning modules in the medical school curriculum, proportional to module size and gender. The interviews were done to all second-year students (learning modules 3 and 4); two first-year (5\%), four third-year (15\%), eight fourth-year (27\%), 14 fifth-year (54\%), and 13 sixth-year students (50\%) did not show up to their scheduled interview. There were 41 losses, mostly fifth- and sixth-year students. The sample included 140 students, but it was not representative of fifth- and sixth-year students as there were only 24 participants (out of 51 drawn; 47\%). The final sample consisted of 120 first- to fourth-year students (out of 489 enrolled in the medical program). All participants signed an informed consent form agreeing to participate in the study.

It was assessed anxiety symptoms, considering psychic and somatic aspects. Demographic data (age and sex) and information on course year, hours of sleep per day, hours of physical exercise per week, and use of anti-anxiety medication were also collected (Annex 1).

Psychic symptoms included worrying too much; feeling "on edge;" difficulty concentrating; trouble relaxing; fearing for the worst; being terrified; being nervous; fear of losing control; fear of dying; and being frightened. Somatic symptoms included numbness or tingling; restlessness; tremors; heat sensation; palpitations or heart racing; dizziness; loss of balance; feeling of choking; difficulty breathing; stomach discomfort, and cold sweating. The institutional ethics committee (protocol no 12353719.0.0000.5383) approved this research.
A psychologist interviewed the participants and asked them to rate their symptoms in the last 10 days. They were classified as $0,1,2,3$, where the higher the score, the more intense the anxiety symptoms were. As the psychologist finished the interviews, the students were classified according to the anxiety's level as "very mild", "mild", "moderate", and "severe", respectively to the sum of scores as 0 to 9, 10 to 19,20 to 29 and 30 and above.

First, it was conducted a pilot test with a subsample of 18 participants, and each student was interviewed twice within ten days to test the intraexaminer agreement of anxiety symptoms.

The dependent variable was anxiety severity (scores) and independent variables included:

- Age: <23 years, 24+ years;

- Gender: male, female;

- Course year: consisted of two consecutive modules - first year(M1 + M2); second year (M3 + M4); third year(M5 + M6); and fourth year(M7 + M8);

- Sleep: inadequate ( $<7$ hours per day); adequate $(7$ to 9 hours per day); ${ }^{10}$

- Physical activity: inactive (sedentary); active (1 hour or more per week) and

- Regular use of anti-anxiety medication (yes / no).

The data was pre-coded, entered into an Excel spreadsheet and analyzed using STATA Statistical Software version 11.2. It was used kappa (к) statistic to test the intra-examiner agreement: $<0.00$ (none); 0.000.20 (slight agreement); 0.21-0.40 (fair agreement); 0.41-0.60 (moderate agreement); 0.61-0.80 (substantial agreement); and 0.81-1 (near-perfect agreement). ${ }^{11}$ Prevalence data were presented by point $(p)$ with respective $95 \%$ confidence intervals $(95 \% \mathrm{Cl})$ and prevalence ratios (PR). It was performed the chi-square test $\left(\chi^{2}\right)$ to test associations of interest at a $5 \%$ significance level.

\section{Results}

The sample consisted of 120 first- to fourth-year medical students, where $66.7 \%$ were female, and the mean age was $22.1 \pm 4.0$ years.

Regarding to the anxiety symptoms formulary, the overall intra-examiner agreement was moderate to near-perfect $(0.51 \leq \mathrm{k} \leq 0.90)$. It was moderate for trouble relaxing $(\kappa=0.55)$ and feeling frightened $(\kappa=0.51)$. The classification was good for worrying too much ( $\kappa=0.67)$, feeling "on edge" $(\kappa=0.68)$, difficulty concentrating $(\kappa=0.78)$, being terrified $(\kappa=0.74)$, being nervous $(\kappa=0.68)$, fearing of losing control $(\kappa=0.62)$ and fear of dying $(k=0.75)$. And it was excellent for tremors $(\kappa=0.90)$, heat sensation $(k=0.90)$, fearing for the worst $(\kappa=0.85)$, dizziness $(\kappa=0.85)$, loss of balance $(\kappa=0.85)$, stomach discomfort $(\kappa=0.84)$, and cold sweating $(\kappa=0.83)$. 
According to Figure 1, the prevalence of moderate and severe anxiety among medical students was $38.3 \%$.

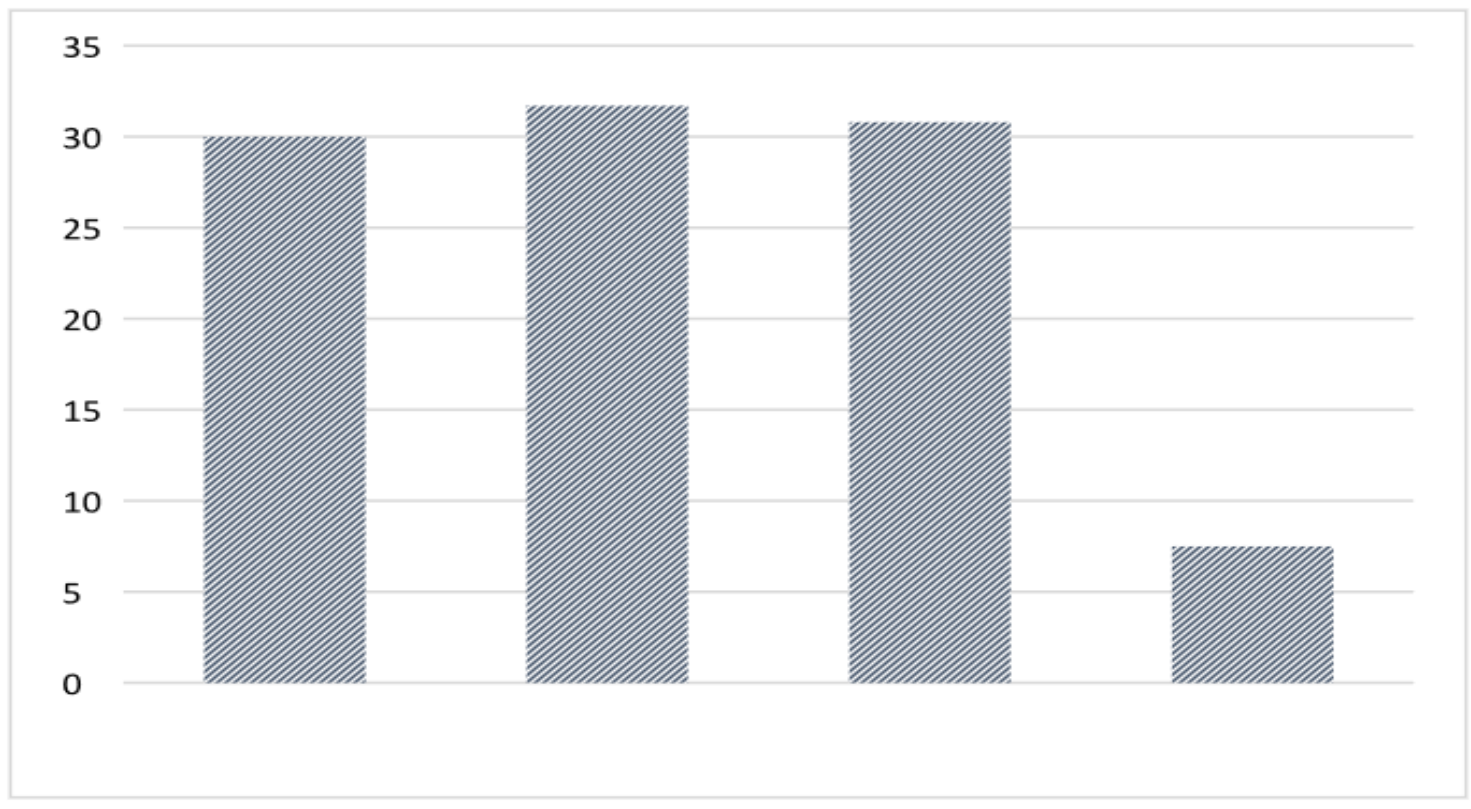

very mild mild moderate severe

Figure 1: Prevalence of medical students' anxiety in a private university, São Paulo State, Brazil

Table 1 shows the prevalence of anxiety severe symptoms of worrying too much (59\%) and symptoms, where most students reported moderate to being nervous (61\%).

Table 1: Prevalence of anxiety symptoms in number (n) and in percentage (\%) according to rate (0: definitely not; 1 : slightly; 2: moderate; 3: severe).

\begin{tabular}{l|cccc}
\hline \multirow{2}{*}{\multicolumn{1}{c|}{ Anxiety symptom }} & 0 & 1 & 2 & 3 \\
\cline { 2 - 5 } & $\mathrm{n} \mathrm{( \% )}$ & $\mathrm{n} \mathrm{( \% )}$ & $\mathrm{n}(\%)$ & $\mathrm{n}(\%)$ \\
\hline Worring too much & $9(8)$ & $40(33)$ & $47(39)$ & $24(20)$ \\
Feeling "on the edge" & $27(23)$ & $43(36)$ & $40(33)$ & $10(8)$ \\
Difficulty concentrating & $31(26)$ & $57(48)$ & $27(23)$ & $5(4)$ \\
Trouble relaxing & $35(29)$ & $43(36)$ & $32(27)$ & $10(8)$ \\
Fearing for the worst & $23(19)$ & $48(40)$ & $29(24)$ & $20(17)$ \\
Being terrified & $83(69)$ & $27(23)$ & $7(06)$ & $3(3)$ \\
Being nervous & $13(11)$ & $34(28)$ & $45(38)$ & $28(23)$ \\
Fear of losing control & $50(42)$ & $36(30)$ & $23(19)$ & $11(9)$ \\
Fear of dying & $94(78)$ & $15(13)$ & $6(5)$ & $5(4)$ \\
Being frightened & $70(58)$ & $30(25)$ & $14(12)$ & $6(5)$ \\
Numbness or tingling & $97(81)$ & $13(11)$ & $6(5)$ & $4(3)$ \\
Restlessness & $41(34)$ & $45(38)$ & $23(9)$ & $11(9)$ \\
Tremors & $93(78)$ & $20(17)$ & $7(6)$ & $-(0)$ \\
Heat sensation & $79(66)$ & $21(18)$ & $17(14)$ & $3(3)$ \\
Palpitation or racing heart & $54(45)$ & $36(30)$ & $22(18)$ & $8(7)$ \\
Dizziness & $89(74)$ & $19(16)$ & $11(9)$ & $1(1)$ \\
Loss of balance & $104(87)$ & $11(9)$ & $4(3)$ & $1(1)$ \\
Feeling of choking & $85(71)$ & $26(22)$ & $5(4)$ & $4(3)$ \\
Difficulty breathing & $100(83)$ & $11(9)$ & $5(4)$ & $4(3)$ \\
Stomach discomfort & $41(34)$ & $40(33)$ & $27(23)$ & $12(10)$ \\
Cold sweating & $67(56)$ & $28(23)$ & $22(18)$ & $3(3)$ \\
\hline
\end{tabular}


a) Anxiety severity in medical students

Thirty-six students showed very mild $(30.0 \%$; 95\%Cl: 21.8\%-38.2\%), 38 mild (31.7\%; 95\% Cl: $23.4-$ 40.0), 37 moderate (30.8\%; 95\% Cl: 22.5-39.1) and 9 severe anxiety (7.5\%; $95 \% \mathrm{Cl}: 2.8-12.2)$. In our sample,
$61.7 \%$ showed very mild/mild and $38.3 \%$ moderate/severe anxiety. Table 2 summarizes the association between the severity of anxiety and the study variables.

Table 2: Association between the severity of anxiety among medical students and the study variables.

\begin{tabular}{|c|c|c|c|c|c|c|c|c|c|}
\hline \multirow{2}{*}{ Variable } & \multicolumn{2}{|c|}{ Verymild } & \multicolumn{2}{|c|}{ Mild } & \multicolumn{2}{|c|}{ Moderate } & \multicolumn{2}{|c|}{ Severe } & \multirow{2}{*}{$\chi^{2}$ (p-value) } \\
\hline & $\mathrm{n}$ & $\%$ & $n$ & $\%$ & $\mathrm{n}$ & $\%$ & $n$ & $\%$ & \\
\hline \multicolumn{10}{|l|}{ Age } \\
\hline$<23$ years & 19 & 20.9 & 31 & 34.1 & 32 & 35.2 & 9 & 9.9 & $16.2858(0.001)^{\star}$ \\
\hline $24+$ years & 17 & 58.6 & 7 & 24.1 & 5 & 17.2 & - & 0.0 & \\
\hline \multicolumn{10}{|l|}{ Gender } \\
\hline Female & 17 & 21.2 & 25 & 31.2 & 31 & 38.7 & 7 & 8.7 & $11.5165(0.009)^{\star}$ \\
\hline Male & 19 & 47.5 & 13 & 32.5 & 6 & 15.0 & 2 & 5.0 & \\
\hline \multicolumn{10}{|l|}{ Courseyear } \\
\hline Firstyear & 9 & 23.1 & 13 & 33.3 & 13 & 33.3 & 4 & 10.3 & $6.2693(0.713)^{\mathrm{ns}}$ \\
\hline Secondyear & 9 & 25.0 & 13 & 36.1 & 11 & 30.6 & 3 & 8.3 & \\
\hline Thirdyear & 10 & 43.5 & 6 & 26.1 & 5 & 21.7 & 2 & 8.7 & \\
\hline Forthyear & 8 & 36.4 & 6 & 27.3 & 8 & 36.4 & 9 & 7.5 & \\
\hline \multicolumn{10}{|l|}{ Sleep } \\
\hline Adequate & 22 & 41.5 & 14 & 26.4 & 14 & 26.4 & 3 & 5.3 & $6.0475(0.109)^{\mathrm{ns}}$ \\
\hline Inadequate & 14 & 20.9 & 24 & 35.8 & 23 & 34.3 & 6 & 8.9 & \\
\hline \multicolumn{10}{|c|}{ Phys. Activity } \\
\hline Inactive & 7 & 29.2 & 6 & 25.0 & 10 & 41.7 & 1 & 4.2 & $2.0143(0.569)^{\mathrm{ns}}$ \\
\hline Active & 29 & 30.2 & 32 & 33.3 & 27 & 28.1 & 8 & 8.3 & \\
\hline \multicolumn{10}{|l|}{ Anti-anxiety } \\
\hline No & 33 & 31.7 & 33 & 31.7 & 32 & 30.8 & 6 & 5.8 & $3.8963(0.273)^{n s}$ \\
\hline Yes & 3 & 18.7 & 5 & 31.2 & 5 & 31.2 & 3 & 18.7 & \\
\hline
\end{tabular}

*significant; ${ }^{\text {ns }}$ non-significant

Anxiety severity was significantly associated with age. The prevalence of moderate anxiety was two times higher in younger $(P R=2.0)$ than older participants. Severe anxiety was seen only in those aged $\leq 23$ years.

Anxiety was significantly associated with being female, which could be explained by a greater proportion of female students showing moderate ( $P R=$ 2.6) and severe level $(P R=1.7)$.

Regarding year course, the association was non-significant. As for sleep (adequate or inadequate), there was a non-significant association with anxiety.

The association between anxiety severity and physical activity was non-significant. On the other hand, moderate anxiety was more prevalent among inactive (41.7\%) than active students (28.1\%) $(P R=1.5)$.

A non-significant association was seen with the use of anti-anxiety medication; however, severe anxiety was more prevalent among students on anti-anxiety medication (18.7\%) than about those not taking any medication $(5.8 \%)(P R=3)$.

\section{Discussion}

This study aimed to assess anxiety among medical students from a private medical education institution in the state of São Paulo, southeast Brazil. A formulary was specifically developed for the assessment of anxiety symptoms (Annex 1, Chart) and administered by a psychologist. After the interview, the psychologist identified the most prevalent anxiety symptoms and classified the students into four groups: very mild, mild, moderate, and severe. Also, the students' demographic data and information on sleep, physical activity, and regular use of anti-anxiety medication were collected. This formulary was reliable, according to the results of the intra-examiner agreement.

The results here presented are for a random sample of first- to fourth-year students ( $n=120 ; 27 \%$ of total students enrolled in these school years). The majority of the students from fifth- and sixth-year was not able to attend the interview, as they spend their day on clinical rotations in health care units, outpatient clinics, and hospitals and work long hours at different services with day and night shifts during the sixth year.

It was used a cross-sectional design, as in most studies of anxiety conducted among university students. ${ }^{12}$ This methodological design does not allow to make inferences about a temporal relationship between experiencing anxiety and the variables (sleep, physical activity, and use of anti-anxiety medication) and know whether exposure is a cause or a consequence of anxiety. Researchers have argued that investigations of anxiety in medical students should use longitudinal designs to identify risk factors associated as they could provide input for developing and implementing 
management strategies in higher education institutions. ${ }^{5,12}$

Of 21 anxiety symptoms assessed, "worrying too much" and "being nervous" were noteworthy as most students reported them with moderate and severe anxiety. As for anxiety severity, 38 students (31.7\%) showed mild, 37 (30.8\%) moderate, and 9severe anxiety (7.5\%). Of all, $36(30 \%)$ showed no symptoms or very mild anxiety.

The association of anxiety with age was statistically significant; anxiety was more prevalent among younger students. A study with undergraduate medical students reported similar anxiety rates with age over the years of a medical program, despite a trend of lower prevalence of anxiety among older students. ${ }^{3}$ It can be speculated that lower prevalence of anxiety in older students may suggest that medical students adapt and overcome adversity over time. In general, young students that have to leave their family to move to college in faraway cities or regions can have psychological disorders.

As for gender, anxiety was more prevalent among women, which is in line with the findings of prior studies. $^{2,7}$ A meta-analysis research involving 40,348 medical students found a non-significant association between anxiety and gender. ${ }^{5}$

About to course year, the association with anxiety was not significant, and corroborated by the findings of a prior study. ${ }^{5}$ On the contrary, another study suggested that stress score was higher as medical students progressed through the year of study. ${ }^{13} \mathrm{~A}$ longitudinal design could be used to investigate this relationship, as it would allow to follow up undergraduate students, and their health status over the years. ${ }^{12}$ Transition from family to university life is critical and first-year students are of greater concern because they have to adjust to college demands and, in 2020, overcome the effects of social and physical isolation due to the current COVID-19 pandemic.

There was no association between anxiety severity and other study variables including sleep and regular physical activity. Numerous studies described sleep and physical activity as protective factors for mental health. ${ }^{14}$ Yet, severe anxiety was more likely among those with inadequate sleep and physically inactive. It was used an exploratory approach with a binary option to assess certain variables including hours of sleep per day, physical activity, and use of antianxiety medication as laid out in the study methodology. Specific instruments should be used in future studies to measure these constructs using similar approaches.

Regular use of anti-anxiety medication did not show a significant association with anxiety. Still, our interpretation of these results was hindered, as it is not known the exact timing of the events, whether they experienced an episode of anxiety and started on anti- anxiety medication, or whether it was the other way around.

We recognize the limitations of this study: one of the main limitations is the non-inclusion of senior-year students in our sample as they could not attend the interviews as mentioned before. Thus, our results are for students going through the basic cycle of medical program, from year 1 to 4 . Another limitation is that our findings cannot be compared to the findings of other studies, as they have used different anxiety assessment such as, the Self-Reporting Questionnaire (SQR-20) for screening common mental disorders, the World Health Organization Quality of Life, brief(WHOQOL-BREF) to assess the quality of life and the BDI to identify depressive symptoms. ${ }^{12}$ According to Mayer, ${ }^{7}$ besides the BDI, the STAI is a widely used inventory for clinical evaluation and research purposes of depression and anxiety and it was validated for use in the Brazilian population.

It is important to differentiate non-pathological anxiety (or social anxiety disorder, SAD) from generalized anxiety disorder (GAD) assessed in our study. While psychosocial functioning is significantly affected in GAD, and people experience intense distress and tend to worry excessively, daily life functioning is not affected in non-pathological anxiety and people can control and overcome their worries and handle more urgent matters. In our study, $30 \%$ of the students showed very low anxiety, which is considered "productive" anxiety, thus potentially boosting people's lives. Yet, $70 \%$ showed mild, moderate and severe anxiety, which could progress to GAD and affect their quality of life.

The truth is that few students with anxiety spontaneously seek help because of the stigma associated with seeking care and treatment for mental health illnesses. ${ }^{8}$ One of the greatest challenges is that medical students tend not to seek out help because they believe their feelings of anxiety and depression are a sign of weakness.

Intense workload, lack of free time, excessive demands on oneself, social stigmatization for seeking mental health support, financial issues, and fear of ruining one's career are factors for not seeking out specialized mental care. Because of its potential to affect students' learning, quality of daily life and professional practice, either during their clinical rotations in the final third of the undergraduate program (not assessed in the present study) or after graduation, it is critical to help them. Thus, it is necessary to develop and implement interventions and activities to help students cope with the demands of a medical program and minimize potential mental health disorders. Some pedagogic strategies as portfolios, mentoring, and feedback must be planned by the educators to favor the development of emotional competencies in medical students. ${ }^{15}$ Moreover, it is concerning that suicidal 
thoughts are prevalent among medical students and other health care students. ${ }^{8}$ It thus reinforces the importance of interventions, as health care students and graduates have more knowledge about effective means to commit suicide. Early identification of anxiety symptoms that may develop into depressive states and suicide thoughts/attempts is critical and should be incorporated into support and care policies for successfully curbing self-destructive behaviors.

It is crucial to identify potential risk factors for emotional distress during medical training and implement prevention and health promotion policies aiming at strengthening students' resilience under conditions of stress and their emotional balance. ${ }^{7}$ Healthy lifestyles, including healthy eating habits, adequate sleep, and physical activity can also be promoted among medical students for improved quality of life. ${ }^{9}$

Strengthening empathy, resilience, and one's ability to adapt well to new learning environments and situations and professional life demands is key to improve the well-being of health care and medical students. These skills are essential for overcoming daily challenges and other emerging challenges as those created by the COVID-19 pandemic worldwide.

\section{Conclusions}

Anxiety is reportedly a prevalent condition among medical students as they face large amount of learning tasks, intensive workloads, and excessive demands.

There was found $31.7 \%$ prevalence of mild, $30.8 \%$ moderate and $7.5 \%$ severe anxiety in medical students. Higher rates of anxiety were seen among females and younger students.

Our findings of anxiety in Brazilian medical students provide input for the development and implementation of strategies at medical education institutions that could minimize emotional distress.

\section{ACKNOWLedgements}

We thank our collaborators Dr. Sérgio Baldassim (Faculdade de Medicina do ABC, São Paulo, Brazil) and Dr Fernanda Brenneisen Mayer (PUC Curitiba, Paraná, Brazil) for their kindness and appropriate careful considerations that contributed greatly to this work.

Authors' contributions:

All authors contributes to the design, analysis and interpretation of the data. All authors revised the article and approved the final version.

\section{References Références Referencias}

1. Hovens JGFM, Giltay EJ, Wiersma JE, Spinhoven P, Penninx BWJH, Zitman FG. Impact of childhood life events and trauma on the course of depressive and anxiety disorders. Acta Psychiatr Scand. 2011; 126(3): 198-207.

2. Baxter AJ, Scott KM, Vos T, Whiteford H. Global prevalence of anxiety disorders: a systematic review and meta-regression. Psychol Med. 2013; 43(5): 897-910.

3. World Health Organization. Depression and other common mental disorders: Global Health Estimates. 2017. Available from: https://apps.who.int/iris/ bitstream/handle/10665/254610/WHO-MSD-MER2017.2-eng.pdf?sequence $=1$. Accessed in 2020 (Jun 20).

4. Costello EJ, Egger HL, Angold A. The developmental epidemiology of anxiety disorders: phenomenology, prevalence, and comorbidity. Child Adolesc Psychiatr Clin Am. 2005; 14(4): 631-48.

5. Quek TTC, Tam WWS, Tran BX, Zhang M, Zhang Z, Ho CS, Ho RC. The Global Prevalence of Anxiety among Medical Students: A Meta-Analysis. Int J Environ Res Public Health. 2019; 16(15): 2735.

6. Baldassin S, Martins LC, Andrade AG. Traces of anxiety among medical students. Arq Med ABC. 2006; 31(1): 27-31.

7. Mayer FB, Santos IS, Silveira PSP, Lopes MHI, de Souza ARND et al. Factors associated to depression and anxiety in medical students: a multicenter study. BMC Med Educ. 2016; 16(1):282.

8. Rotenstein LS, Ramos MA, Torre M, Segal JB, Peluso MJ et al. Prevalence of Depression and Suicidal Ideation Among Medical Students: A Systematic Review and Meta-Analysis. JAMA. 2016; 316(21): 2214-36.

9. Tempski P, Bellodi PL, Paro HB, Enns SC, Martins MA, Schraiber LB. What do medical students think about their quality of life? A qualitative study. BMC Med Educ. 2012; 12(1):106.

10. Hirskowitz M, Whiton K, Albert SM, Vitiello MV, Ware JC, Hillard PJA. National Sleep Foundation's Sleep Time Duration Recommendations: Methodology and Results Summary. Sleep Health. 2015; 1(1): 40-43.

11. Landis JR, Koch GG. The measurement of observer agreement for categorical data. Biometrics. 1977; 33(1):159-74.

12. Conceição LS, Batista CB, Dâmaso JGB, Pereira BS, Carniele RC, Pereira G dos S. Saúde mental dos estudantes de medicina brasileiros: uma revisão sistemática da literatura. Avaliação. 2019; 24(3): 785-802.

13. Ogawa $S$, Kitagawa $Y$, Fukushima M, Hiromi $Y$, Nishida A, Togo F, Sasaki T. Interactive effect of sleep duration and physical activity on anxiety/depression in adolescentes. Psychiatry Research. 2019; 273:456-60.

14. Niemi P, Vainiomaki P. Medical students' distressquality, continuity and gender differences during a 
six-year medical programme. Med Teach 2006; 136-141.

15. Tempski P, Martins AM, Paro HBMS. Teaching and learning resilience: a new agenda in medical education. Med Educ. 2012; 46:345-346.

The Anxiety Symptoms Formulary

Name:

ANNEX 1

Age (years): -----Gender: ........Learning module:

Hours of sleep per day: ....... Hours of physical exercise per week:.....

Regular use of anti-anxiety medication: () yes () no

Chart. The Anxiety Symptom Formulary

\begin{tabular}{|l|l|l|l|l|l|}
\hline \multicolumn{1}{|c|}{ DOMAIN } & \multicolumn{1}{|c|}{ ANXIETY SYMPTOM } & 0 & 1 & 2 & 3 \\
\hline PSYCHIC & Worrying too much & & & & \\
& Feeling "on the edge" & & & \\
Difficulty concentrating & Trouble relaxing & & & \\
Fearing for the worst & Being terrified \\
Being nervous & Fear of losing control & & & \\
Fear of dying & Being frightened & & & \\
\hline SOMATIC & $\begin{array}{l}\text { Numbness or tingling } \\
\text { Restlessness } \\
\text { Tremors } \\
\text { Heat sensation } \\
\text { Palpitation or racing heart } \\
\text { Dizziness } \\
\text { Loss of balance } \\
\text { Feeling of choking } \\
\text { Difficulty breathing } \\
\text { Stomach discomfort } \\
\text { Cold sweating }\end{array}$ & & & & \\
\hline
\end{tabular}

